\title{
Enhanced Boost Factor for Three-Level Quasi-Switched Boost T-Type Inverter
}

\author{
Duc-Tri Do $\mathbb{D}^{\circ}$, Vinh-Thanh Tran and Minh-Khai Nguyen * \\ Faculty of Electrical and Electronics Engineering, Ho Chi Minh City University of Technology and Education, \\ Ho Chi Minh City 700000, Vietnam; tridd@hcmute.edu.vn (D.-T.D.); thanhtv.ncs@hcmute.edu.vn (V.-T.T.) \\ * Correspondence: khainm@hcmute.edu.vn; Tel.: +84-28-3722-1223
}

check for updates

Citation: Do, D.-T.; Tran, V.-T.;

Nguyen, M.-K. Enhanced Boost

Factor for Three-Level

Quasi-Switched Boost T-Type

Inverter. Energies 2021, 14, 3920.

https: / / doi.org/10.3390/

en14133920

Academic Editor: Jung-Wook Park

Received: 27 May 2021

Accepted: 28 June 2021

Published: 30 June 2021

Publisher's Note: MDPI stays neutral with regard to jurisdictional claims in published maps and institutional affiliations.

Copyright: (C) 2021 by the authors Licensee MDPI, Basel, Switzerland. This article is an open access article distributed under the terms and conditions of the Creative Commons Attribution (CC BY) license (https:/ / creativecommons.org/licenses/by/ $4.0 /)$.

\begin{abstract}
A new modulation strategy has been introduced in this paper in order to enhance the boost factor for the three-level quasi-switched boost T-type inverter (3L-qSBT ${ }^{2}$ I). Under this approach, the component rating of power devices is significantly decreased. Moreover, the use of a larger boost factor produces a smaller shoot-through current. This benefit leads to reducing the conduction loss significantly. Furthermore, the neutral voltage unbalance is also considered. The duty cycle of two active switches of a quasi-switched boost (qSB) network is redetermined based on actual capacitor voltages to recovery balance condition. Noted that the boost factor will not be affected by the proposed capacitor voltage balance strategy. The proposed method is taken into account to be compared with other previous studies. The operation principle and overall control strategy for this configuration are also detailed. The simulation and experiment are implemented with the help of PSIM software and laboratory prototype to demonstrate the accuracy of this strategy.
\end{abstract}

Keywords: third harmonic injection; single-stage inverter; shoot-through; three-level inverter; quasiswitched boost; T-type inverter

\section{Introduction}

Currently, a conventional three-level T-type inverter (3L- $\left.\mathrm{T}^{2} \mathrm{I}\right)$ is applied for low voltage applications due to its advantages of low conduction loss due to not using extra diodes compared to neutral point clamped inverter (NPCI) configuration or producing better output quality compared to two-level inverter [1,2]. This topology is recently adopted for many applications, especially photovoltaic (PV) systems and motor drives, etc. [3-5]. Nevertheless, the traditional 3L-T ${ }^{2}$ I produces a low value of AC output voltage in comparison to the input voltage of the inverter. Moreover, the conventional 3L- $\mathrm{T}^{2} \mathrm{I}$ cannot accept the shoot-through (ST) state during operation because of leading to a short circuit at the DC input source.

Nowadays, impedance-source inverters have been considered as a solution to deal with the drawbacks of conventional inverters [6-8]. By using some passive components such as diodes, capacitors, and inductors in Z-source (ZS) circuit, the ZS inverter (ZSI) can behave as a buck-boost inverter with ST immunity. During operation, the ST state is utilized to belong to traditional vectors of the inverter to enhance the output voltage. The result is that the reliability is significantly improved. According to these advantages, several applications based on ZSI were discussed for the motor drive system, micro-grid connection, and PV applications [9,10]. Many traditional multilevel inverter topologies were considered to incorporate with the ZS network, such as NPCI and 3L-T ${ }^{2}$ I [11-14]. The works in $[15,16]$ introduced a topology combining a single ZS network and 3L-T ${ }^{2} \mathrm{I}$. To ensure a three-level voltage operation, this combination uses a split DC input source. The neutral point of this source is utilized to belong to of ZS circuit to feed to the three-level inverter circuit. This configuration must use one extra diode to guarantee the symmetry of the impedance network. Instead of using full-ST (FST) state, this method used upper-ST (UST) and lower-ST(LST) states to conform to the buck-boost characteristic, which is added 
within small vectors. In this strategy, the boost factor is equal to the traditional strategy in [8]. The work in [16] further proposed the neutral voltage balance strategy. However, this strategy required more dwell-time calculations and caused the boost factor effect.

To produce less component voltage rating and draw continuous input current, the quasi-Z-source (qZS) inverter (qZSI) has been presented in [17-22]. These topologies use the same components compared to ZSI, but these components were connected in another way. Like the ZS network, this type of impedance-source structure was considered to incorporate with the three-level inverter to provide multilevel characteristics [17-22]. In these approaches, two qZS circuits are connected to guarantee three-level operation at the output. However, the use of a large number of inductors and capacitors leads to increase volume and decrease power density of the inverter. Furthermore, buck-boost characteristics of the ZS/qZS inverters are only ensured by the ST duty ratio of the inverter branch, which decreases the flexibility of boost factor regulation. The literature [20] introduced the spacevector-modulation (SVM) method and the third harmonic injection scheme, which ensure the buck-boost operation by applying the UST and LST states. Similar to ZSI, these schemes required a split DC source to conduct UST and LST insertions. In [21,22], a novel SVM strategy was proposed to reduce the amplitude and the slew rate $\mathrm{dv} / \mathrm{dt}$ of common-mode voltage (CMV). In this work, the neutral voltage unbalance problem was handled by adding one more extra small vector into the traditional switching sequence. However, the drew-time of additional small vectors is hardly determined. It produces the complexity of the calculation.

The quasi-switched boost (qSB) inverter (qSBI) was considered as an emerging topology that saves plenty of inductors and capacitors [23-30]. By installing one more active switch in the intermediate circuit, the boost factor of qSBI is so flexible to be controlled [16]. In this configuration, some advantages can be listed as high boost factor and voltage gain and good inductor current profile. These advantages lead to reducing voltage stresses on power devices and less capacitance requirement for passive components such as inductors and capacitors. The works of literature in [25-30] proposed the incorporation between qSB network and the multilevel inverter. In $[25,26]$, the three-level NPCI was combined with two separated qSB networks. The 3L-T ${ }^{2} \mathrm{I}$ was considered to combine with this type of impedance-source network in [27-30]. In [27-30], the qSB network utilized only one inductor and one DC input source, which saves one inductor and a split DC source compared to [25]. These works also proposed a new pulse-width modulation (PWM) strategy based on the phase shift carrier method to provide some benefits such as high voltage gain [21,27], common-mode voltage elimination [28], the capability of operating in normal and open-circuit faults [29], and small component rating. Similar to other types of single-stage buck-boost inverter, this configuration also utilizes the FST state to obtain buck-boost voltage capability, which is inserted within a zero vector to not affect the other voltage vectors. The closed-loop control is employed for capacitor voltage balance, which requires a larger time interval for neutral voltage recovery. The work in [30] adopted a corresponding small vector to balance the neutral voltage. However, this way introduced more CMV amplitude, which is generated by small vectors.

In this paper, a new PWM method is introduced, which improves the boost factor as well as voltage gain of this configuration. The neutral voltage balance is also considered in this paper. Unlike the methods in [16,22,30], where the neutral-voltage balance is ensured by corresponding small vectors of the inverter side, the active switches of the impedancesource network are utilized to balance neutral voltage. The duty cycle difference of these switches is determined based on actual capacitor voltages. This method brings benefits of reducing balancing recovery time and calculation complexity compared to [16,22,27]. The duty cycle of these switches and modulation index are considered to adjust the output voltage of the impedance-source circuit and AC output voltage. The operation modes, as well as the mathematical analysis, will be presented in this paper. Some simulation and experiment setups are used to confirm the accuracy of the proposed modulation method. The rest of this paper consists of four sections as follows. Section 2 introduces the operation 
of the inverter and proposed PWM strategy. Section 3 presents a neutral voltage balancing scheme. In Section 4, a comparison study has been conducted to highlight the contribution of this scheme. In Section 5, the simulation and experimental results have been presented to confirm the accuracy of the introduced method. Section 6 presents a conclusion.

\section{Proposed PWM Scheme for $3 \mathrm{~L}-q S B T^{2} I$}

The $3 \mathrm{~L}-\mathrm{qSBT}{ }^{2} \mathrm{I}$ is established by an impedance-source network and a $3 \mathrm{~L}-\mathrm{T}^{2} \mathrm{I}$, as observed in Figure 1. The impedance-source network is constructed by two switches $S_{1}$ and $S_{2}$, four diodes $D_{1}, D_{2}, D_{3}$, and $D_{4}$, two capacitors $C_{1}$ and $C_{2}$, and one inductor $L_{B}$. The outputs of the intermediate circuit are " $P$ ", " $O$ ", and " $N$ ", which are used to ensure the three-level operation of the inverter. The three-phase resistive load is adopted to confirm the operation of the inverter with the proposed scheme, which is fed through a three-phase LC filter to guarantee the sinusoidal waveform of output load voltage with a low THD value, as depicted in Figure 1. The control scheme of this configuration is detailed in the rest of this section. The operating modes, steady-state analysis, and parameter selection are also presented.

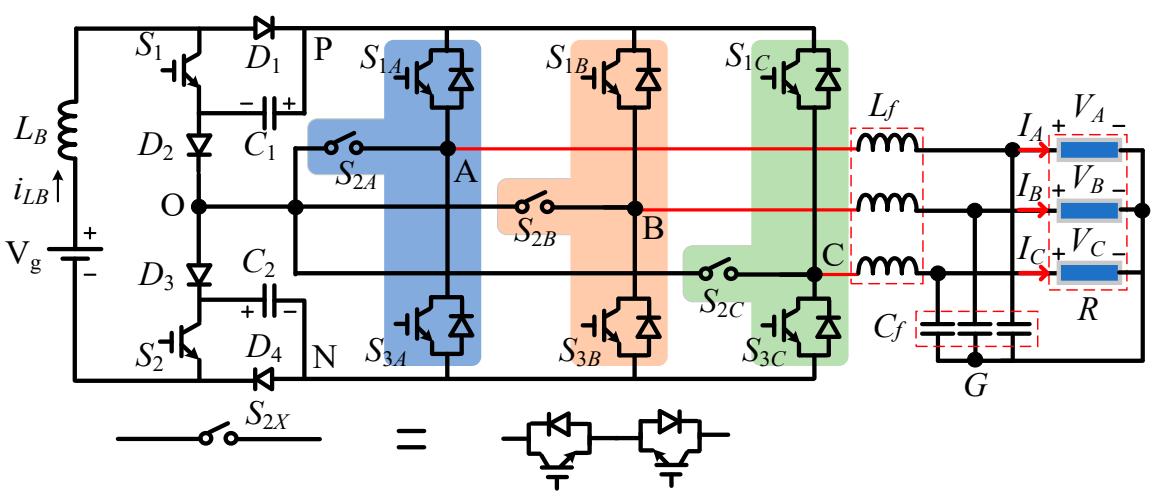

Figure 1. 3L-qSBT ${ }^{2}$ I topology [27].

\subsection{PWM Signal Generation}

The control method for the $3 \mathrm{~L}-\mathrm{qSBT}{ }^{2} \mathrm{I}$ is based on a phase-shift sinusoidal PWM scheme. The PWM control signal generation is divided into two cases: (1) inverter side PWM generation and (2) impedance-source switch PWM generation. For the inverter side, the six reference sinusoidal signals $\left( \pm v_{\mathrm{a}}, \pm v_{\mathrm{b}}\right.$, and $\pm v_{\mathrm{c}}$ ) are compared with a high-frequency triangle signal $\left(V_{\text {tri } 1}\right)$ to generate control signals for the inverter switches. Figure 2 shows the control signal generation for switches of phase A. In detail, switch $S_{1 A}$ is turned on when $-v_{\mathrm{a}}<V_{t r i 1}<+v_{\mathrm{a}}$, switch $\mathrm{S}_{3 \mathrm{~A}}$ is triggered on when $+v_{\mathrm{a}}<V_{t r i 1}<-v_{\mathrm{a}}$, and switch $\mathrm{S}_{2 \mathrm{~A}}$ is turned on when switches $S_{1 A}$ and $S_{3 A}$ are off. Signals $V_{S T}$ and $-V_{S T}$ are used to create the ST signal denoted by yellow highlight in Figure 2. This ST state is generated by turned on all switches on the inverter side. In order not to affect the output voltage, the $V_{S T}$ must not be smaller than the peak value of reference signals.

For the impedance source side, the triangle signal $\left(V_{t r i 2}\right)$ is used, which is shifted 90 degrees compared to $V_{\text {tri1 }}$ to create the control signals for the active switches of the impedance-source network [27]. Signals $V_{S T}$ and $-V_{S T}$ are also used with $V_{t r i 2}$ to generate the ST signal of the intermediate network, which is denoted by green highlight, as shown in Figure 2. Furthermore, two control signals, $V_{c o n} 1$ and $V_{\text {con2, }}$, are further used to enhance the duty ratio of $S_{1}$ and $S_{2}$, as illustrated in Figure 2 .

\subsection{Operating Modes}

Based on the PWM strategy presented in Figure 2, the inverter can be operated under two modes which are ST and non-ST (NST) modes. These modes are divided into five modes, which are ST mode, NST mode 1 , NST mode 2 , NST mode 3 , and NST mode 4 , 
as observed in Figure 3. To simplify, in non-ST modes, the inverter side is considered a current source, $i_{O}$. The on switches and forwarded diodes are shown in Table 1.

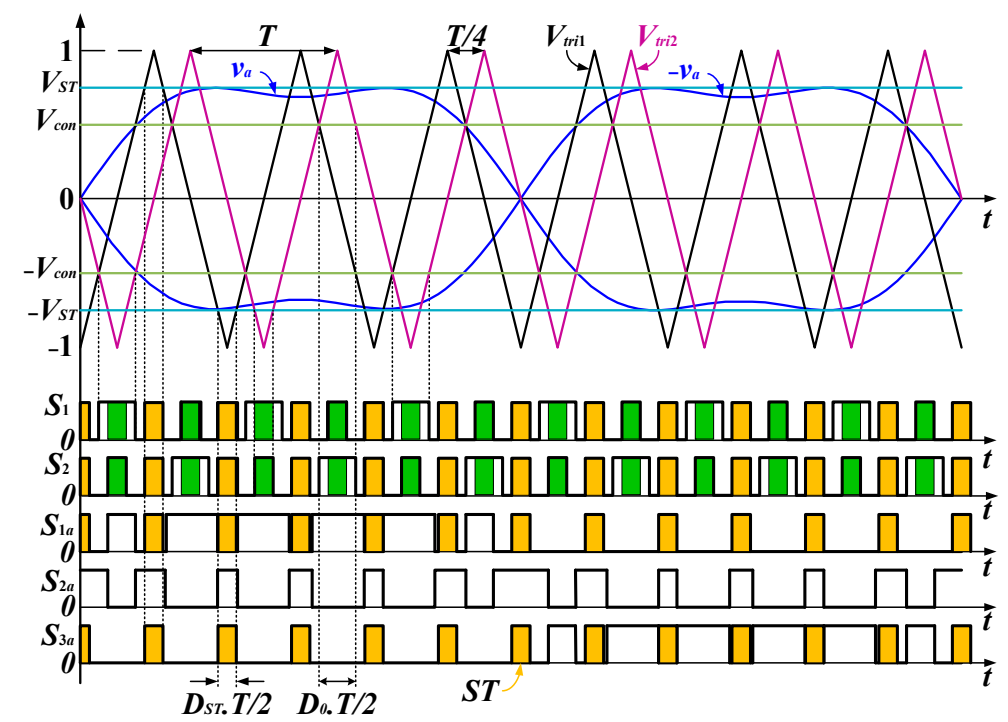

Figure 2. The proposed PWM scheme.

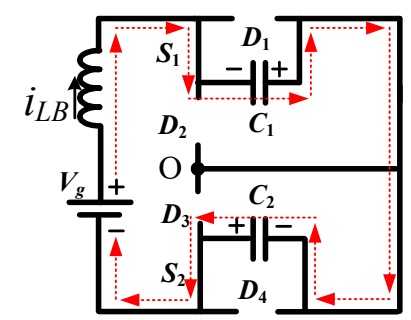

(a)

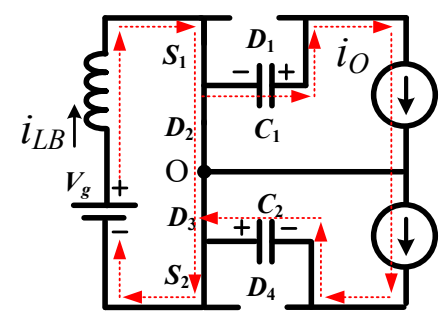

(d)

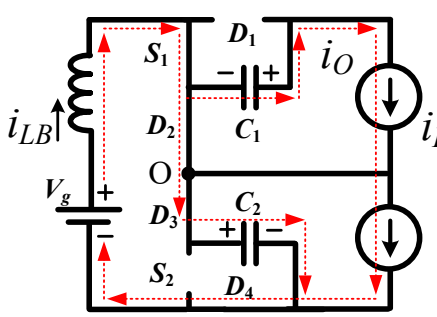

(b)

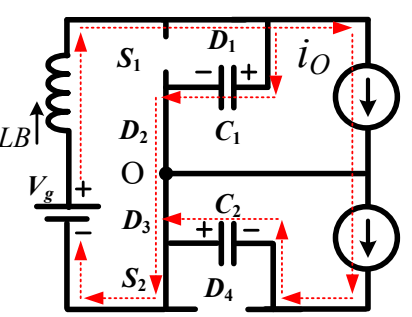

(c)

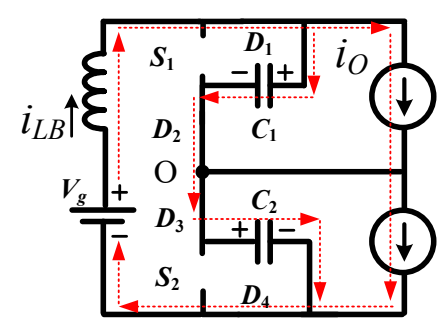

(e)

Figure 3. The modes of 3L-qSBT ${ }^{2}$ I: (a) ST mode, (b) NST mode 1, (c) NST mode 2, (d) NST mode 3, and (e) NST mode 4.

Table 1. On/Off states of $3 \mathrm{~L}-\mathrm{qSBT}{ }^{2} \mathrm{I}$ switches and diodes $(X=A, B, C)$.

\begin{tabular}{cccc}
\hline Mode & ON Switches & ON Diodes & $V_{\text {XO }}$ \\
\hline NST mode 1 & $S_{1}$ & $D_{2}, D_{3}, D_{4}$ & $+V_{P N} / 2,0$ or $-V_{P N} / 2$ \\
NST mode 2 & $S_{2}$ & $D_{1}, D_{2}, D_{3}$ & $+V_{P N} / 2,0$ or $-V_{P N} / 2$ \\
NST mode 3 & $S_{1}, S_{2}$ & $D_{2}, D_{3}$ & $+V_{P N} / 2,0$ or $-V_{P N} / 2$ \\
\hline & $S_{1 X}$ & & $+V_{P N} / 2$ \\
NST mode 4 & $S_{2 X}$ & $D_{1}, D_{2}, D_{3}, D_{4}$ & $-V_{P N} / 2$ \\
\hline ST mode & $S_{3 X}$ & & 0 \\
\hline
\end{tabular}


In ST mode, both switches $S_{1}$ and $S_{2}$ of the qSB circuit and all switches of inverter side are turned on at the same time. The result is that input inductor $L_{B}$ is stored energy from the input source and $C_{1}$ and $C_{2}$ capacitors, as shown in Figure 3a. Conversely, methods in $[27,30]$ only turned on all switches of inverter side, which decrease energy stored in the inductor and boost factor. The voltage across inductor $L_{B}$ and current across two capacitors are expressed as

$$
\left\{\begin{array}{l}
L_{B} \frac{d i_{L B}}{d t}=V_{g}+V_{C 1}+V_{C 2} \\
C_{1} \frac{d v_{C 1}}{d t}=C_{2} \frac{d v_{C 2}}{d t}=-i_{L B}
\end{array}\right.
$$

In NST mode 1 and NST mode 2, as shown in Figure 3b,c, capacitors $C_{1}$ and $C_{2}$ are respectively charged from the DC input source and the energy of inductor $L_{B}$. The following equations are obtained as

$$
\begin{aligned}
& \left\{\begin{array}{l}
L_{B} \frac{d i_{L B}}{d t}=V_{g}-V_{C 2} \\
C_{1} \frac{d v_{C 1}}{d t}=-i_{O}, C_{2} \frac{d v_{C 2}}{d t}=i_{L B}-i_{O}
\end{array}\right. \\
& \left\{\begin{array}{l}
L_{B} \frac{d i_{L B}}{d t}=V_{g}-V_{C 1} \\
C_{1} \frac{d v_{C 1}}{d t}=i_{L B}-i_{O}, C_{2} \frac{d v_{C 2}}{d t}=-i_{O}
\end{array}\right.
\end{aligned}
$$

where $i_{O}$ is the equivalent output current.

In NST mode 3, as illustrated in Figure 3d, the inductor $L_{B}$ is stored energy from the DC input power supply, whereas two capacitors, $C_{1}$ and $C_{2}$, transfer energy to the load. The inductor voltage and capacitor currents are expressed as

$$
\left\{\begin{array}{l}
L_{B} \frac{d i_{L B}}{d t}=V_{g} \\
C_{1} \frac{d v_{C 1}}{d t}=C_{2} \frac{d v_{C 2}}{d t}=-i_{O}
\end{array}\right.
$$

NST mode 4 is shown in Figure 3e, the lower capacitor and upper capacitor are further stored energy in NST modes 1 and 2. In these modes, the voltage across the input inductor and capacitor currents are calculated as

$$
\left\{\begin{array}{l}
L_{B} \frac{d i_{L B}}{d t}=V_{g}-V_{C 1}-V_{C 2} \\
C_{1} \frac{d v_{C 1}}{d t}=C_{2} \frac{d v_{C 2}}{d t}=i_{L B}-i_{O}
\end{array}\right.
$$

\subsection{Steady-State Analysis}

The key waveform of inductor current $i_{L B}$ and capacitor voltages $V_{C 1}$ and $V_{C 2}$ are depicted in Figure 4. Considering one switching period, the time intervals of ST state is $D_{S T}$.T. The time interval of NST mode 3 is also $D_{S T}$.T. The total time interval of NST mode 1 and NST mode 2 is $\left(D_{0}-D_{S T}\right) T$. The rest time of switching period is $\left(1-D_{0}-D_{S T}\right) T$, which is the time interval of NST mode 4 . The average values of inductor voltage $\left(\bar{V}_{L B}\right)$ and capacitor currents $\left(\bar{I}_{C 1}, \bar{I}_{C 2}\right)$ are calculated as in Equation (6). Noted that the following equations are achieved by considering $V_{C 1}=V_{C 2}$.

$$
\left\{\begin{array}{l}
\bar{V}_{L}=\left[\left(V_{g}+2 V_{C 1}\right) D_{S T} T+\left(V_{g}-V_{C 1}\right)\left(D_{0}-D_{S T}\right) T\right. \\
\left.+V_{g} D_{S T} T+\left(V_{g}-2 V_{C 1}\right)\left(1-D_{0}-D_{S T}\right) T\right] / T \\
\bar{I}_{C 1}=\bar{I}_{C 2}=\left[-i_{L B} D_{S T} T-i_{O}\left(D_{0}-D_{S T}\right) T / 2+\left(i_{L B}-i_{O}\right)\left(D_{0}-D_{S T}\right) T / 2\right. \\
\left.-i_{O} D_{S T} T+\left(i_{L B}-i_{O}\right)\left(1-D_{0}-D_{S T}\right) T\right] / T
\end{array}\right.
$$




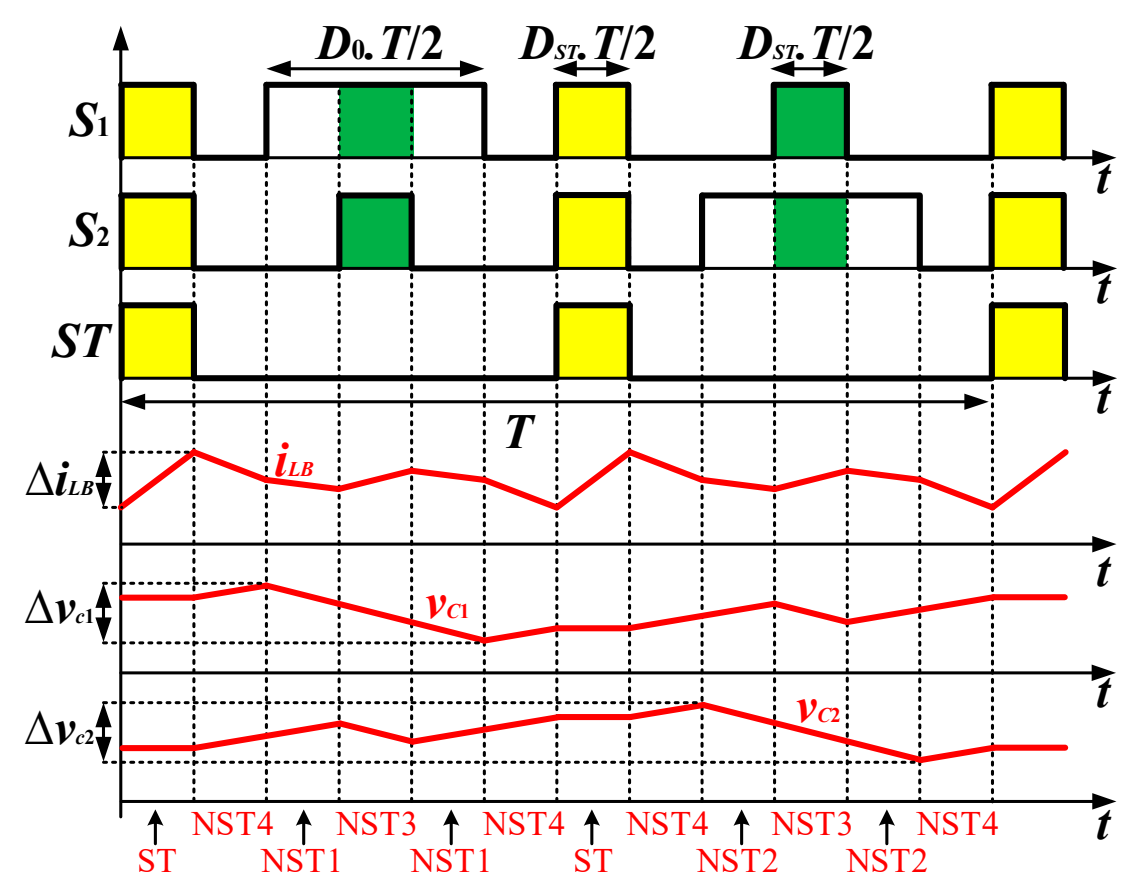

Figure 4. The key waveform in switching period.

In steady-state, these average values are equal to zero, thus the capacitor voltages and average value of inductor current can be expressed as:

$$
\left\{\begin{array}{l}
V_{C 1}=V_{C 2}=\frac{V_{g}}{2-5 D_{S T}-D_{0}} \\
I_{L B}=2 i_{O} \frac{1-D_{S T}}{2-5 D_{S T}-D_{0}}
\end{array}\right.
$$

The max value of $V_{P N}$ voltage is identified by summing of two capacitor voltages and expressed as

$$
V_{P N}=V_{C 1}+V_{C 2}=\frac{2 V_{g}}{2-5 D_{S T}-D_{0}}
$$

The boost factor is defined as

$$
B=\frac{V_{P N}}{V_{g}}=\frac{2}{2-5 D_{S T}-D_{0}}
$$

The first-order of output load voltage is identified as

$$
V_{x, \text { peak }}=1.15 M V_{P N} / 2=\frac{1.15 M V_{g}}{2-5 D_{S T}-D_{0}}
$$

The voltage gain, $G$, is calculated as

$$
G=\frac{V_{x, \text { peak }}}{V_{g} / 2}=\frac{2 \cdot 1.15 M}{2-5 D_{S T}-D_{0}}
$$

The relationship between two coefficients, $D_{S T}$ and $D_{0}$, is defined as

$$
D_{S T} \leq D_{0} \leq 1-D_{S T}
$$


From Equation (12), by adopting $D_{S T}$ and $1-D_{S T}$ for the coefficient $D_{0}$, the minimum and maximum voltage gain is identified by the following equation, noting that the value $(1-M)$ is employed for $D_{S T}$

$$
\left\{\begin{array}{l}
G_{\min }=1.15 M /(3 M-2) \\
G_{\max }=2 \cdot 1.15 M /(6 M-5)
\end{array}\right.
$$

\subsection{Parameter Selection}

The inductor current ripple $\left(\Delta i_{L B}\right)$, illustrated in Figure 4 , is calculated with the help of Equation (1) as

$$
\Delta i_{L B}=\frac{1}{2 L_{B} f_{S}} V_{g} D_{S T}\left(1+\frac{2}{2-5 D_{S T}-D_{0}}\right)
$$

where $f_{S}$ is the switching frequency.

Inductance, $L_{B}$, is selected in term of $\Delta i_{L B} / i_{L B} \leq \% x$ as

$$
L_{B} \geq \frac{\mu}{2 P_{O} \% x f_{S}} V_{g}^{2} D_{S T}\left(1+\frac{2}{2-5 D_{S T}-D_{0}}\right)
$$

where $\% x, \mu$, and $P_{O}$ are the maximum percentage of inductor current ripple, the inverter efficiency, and the output power.

The peak-to-peak value of capacitor voltages, $V_{C 1}$ and $V_{C 2}$, illustrated in Figure 4 , is calculated as

$$
\Delta v_{C 1}=\Delta v_{C 2}=\frac{1}{2 C f_{s}} D_{0} i_{O}
$$

The selection of capacitors, $C_{1}$ and $C_{2}$, is conducted in terms of $\Delta v_{C} / V_{C} \leq \% y$ as follows

$$
C_{1}=C_{2} \geq \frac{1}{4 \% y f_{s}} D_{0} \frac{P_{O}\left(2-5 D_{S T}-D_{0}\right)^{2}}{\mu V_{g}^{2}\left(1-D_{S T}\right)}
$$

where $\% y$ is the maximum percentage of capacitor voltage ripple.

The voltage stresses of impedance switches and diodes are the same as capacitor voltage. The max currents of switches and diodes of the qSB circuit are equal to the max value of the current across the inductor $\left(i_{L B, p e a k}\right)$, which is calculated as

$$
i_{L B, p e a k}=\frac{\mu P_{O}}{V_{g}}+\frac{1}{4 L_{B} f_{S}} V_{g} D_{S T}\left(1+\frac{2}{2-5 D_{S T}-D_{0}}\right)
$$

The current stresses of $3 \mathrm{~L}-\mathrm{T}^{2} \mathrm{I}$ switches are selected as

$$
\left\{\begin{array}{c}
I_{S x y}=i_{O}, \quad \text { when } 13 D_{S T}+3 D_{0} \leq 4 \\
I_{S x y}=i_{L B} / 3,
\end{array}\right.
$$

where $S_{x y}(x=1,2,3 ; y=A, B, C)$ is the inverter side switch. The voltage across $S_{1 X}$ and $S_{3 X}$ is the same as the DC-link voltage, whereas it is half of the capacitor voltage for bidirectional switches.

\section{Proposed Capacitor Voltage Balance Scheme and DC-Link Voltage Control}

As illustrated in Figure $3 b$, in NST mode 1, the capacitor $C_{1}$ is discharged, whereas the capacitor $C_{2}$ is stored energy from the input DC source and the input inductor $L_{B}$. Therefore, in this mode, the voltage across $C_{1}$ is reduced, while $C_{2}$ voltage is raised. As opposed to NST mode 1 , the $C_{1}$ voltage is raised, while the $C_{2}$ voltage is reduced, in NST mode 2, as illustrated in Figure 3c. Noted that these modes generate the same inductor voltage, $V_{L B}=V_{g}-V_{C}$, in terms of achieving a small difference between two capacitor voltages. Therefore, the boost factor is not much affected when replacing the NST mode 1 to NST mode 2 , and vice versa. 
To achieve a balancing condition, the proposed method replaces the NST mode 2 with NST mode 1 when $V_{C 1}>V_{C 2}$. Conversely, NST mode 2 is utilized instead of NST mode 1 when $V_{C 2}>V_{C 1}$, as presented in Figure 5. The $S_{1}$ and $S_{2}$ pulses are responsible for doing this work, which is detailed as follows. First, the traditional pulses of $S_{1}$ and $S_{2}$ are generated by using the $V_{t r i 2}, \pm V_{S T}$, and $\pm V_{c o n}$, as shown in Figure 5 . Then, $V_{C 1}$ and $V_{C 2}$ are considered to generate the final pulses of $S_{1}$ and $S_{2}$. Accordingly, the duty ratio of $S_{2}$ is enhanced when $V_{C 1}>V_{C 2}$. In contrast, the pulse of switch $S_{1}$ is enhanced when $V_{C 2}>V_{C 1}$.

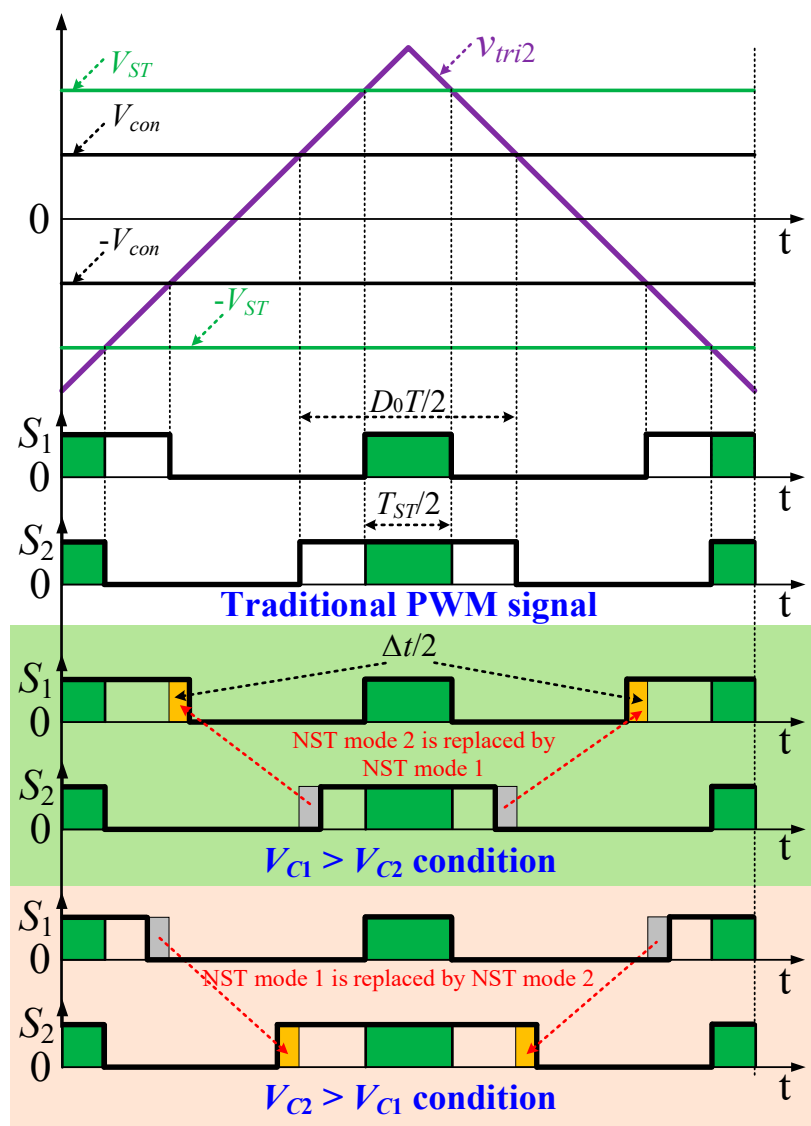

Figure 5. PWM generation for capacitor voltage balance.

In order to detail this strategy, the difference between the two capacitor voltages is defined as

$$
v_{d i f}=V_{C 1}-V_{C 2}
$$

where:

$v_{\text {dif }}$-the difference voltage between $V_{C 1}$ and $V_{\mathrm{C} 2}$.

The total time offset, which is used to replace the NST mode 1 with NST mode 2 and vice versa, is identified as

$$
\Delta t=\alpha t_{N S T 1}=\alpha t_{N S T 2}=\alpha\left(D_{0}-D_{S T}\right) T / 2
$$

where:

$\Delta t$ - the time offset between NST mode 1 and NST mode 2 in one switching period;

$t_{\text {NST1 }}$ and $t_{\text {NST2 }}$ - the traditional time intervals of the NST mode 1 and NST mode 2 , respectively:

$\alpha$-is the offset duty ratio $(0<\alpha \leq 1)$.

The capacitor voltage balance strategy is analyzed in two cases that depend on the $\operatorname{sign}$ of $v_{\text {dif }}$. 
In case 1 , the sign of $v_{d i f}$ is positive. To achieve capacitor voltage balance, in each switching period, the total time of the NST1 and NST2 can be redefined as

$$
\left\{\begin{aligned}
t^{\prime}{ }_{N S T 1} & =t_{N S T 1}+\Delta t=(1+\alpha)\left(D_{0}-D_{S T}\right) T / 2 \\
t^{\prime}{ }_{N S T 2} & =t_{N S T 2}-\Delta t=(1-\alpha)\left(D_{0}-D_{S T}\right) T / 2
\end{aligned}\right.
$$

where $t^{\prime}{ }_{N S T 1}$ and $t^{\prime}{ }_{\text {NST2 }}$ are the redefined time interval of NST mode 1 and NST mode 2 in one switching period.

In case 2 , the sign of $v_{d i f}$ is negative. To obtain capacitor voltage balance, in each switching period, the total time of NST mode 1 and NST mode 2 can be redefined as

$$
\left\{\begin{array}{l}
t^{\prime}{ }_{N S T 1}=t_{N S T 1}-\Delta t=(1-\alpha)\left(D_{0}-D_{S T}\right) T / 2 \\
t^{\prime}{ }_{N S T 2}=t_{N S T 2}+\Delta t=(1+\alpha)\left(D_{0}-D_{S T}\right) T / 2
\end{array}\right.
$$

Noted that the larger value of $\alpha$ leads to the faster neutral voltage balance speed. Moreover, having a fixed difference time $\Delta t$ between on-times of switches $S_{1}$ and $S_{2}$ makes this scheme easier to be employed than the method in [27]. As mentioned above, in this method, the operation of the inverter side is maintained, and the replacement of NST modes 1 and 2 produces the same voltage across the boost inductor. Therefore, this work does not affect the boost factor and voltage gain.

The control block diagram for the inverter is presented in Figure 6. In this figure, the controller consists of two separated parts, the DC-link voltage and AC output voltage regulations. From Equation (8), $V_{P N}$ can be regulated through two coefficients, $D_{S T}$ and $D_{0}$. Like [27], this scheme also fixes the value $D_{S T}$ based on the DC source range. The result is that $V_{P N}$ is controlled through coefficient $D_{0}$. Based on Equation (10), the AC output voltage control is achieved by adjusting capacitor voltage and modulation index $M$. However, when $V_{P N}$ regulation is obtained, the capacitor voltage is fixed at half of DC-link voltage $V_{P N} / 2$. Therefore, the AC voltage regulation is obtained by selecting the corresponding value of $M$.

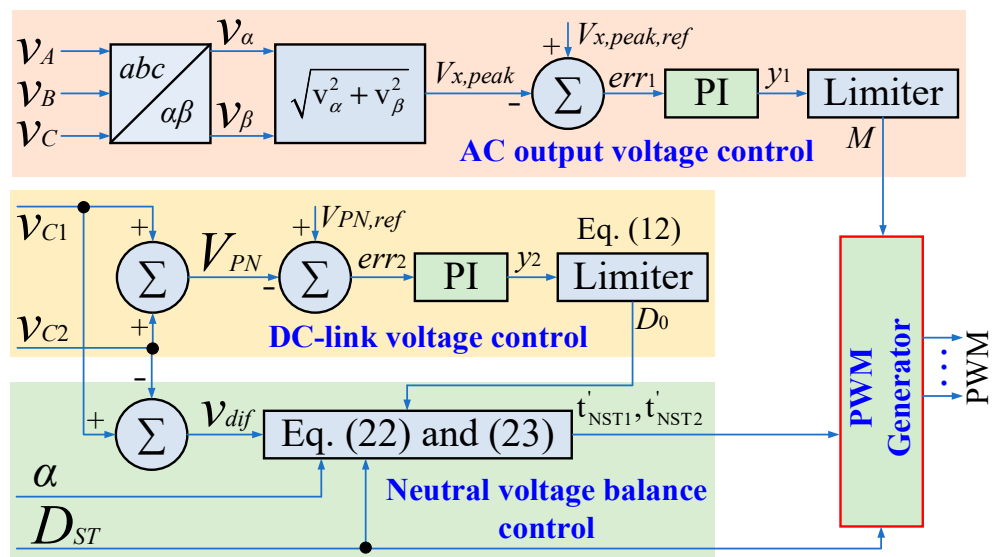

Figure 6. Coordinate control between capacitor voltage balance and DC-link voltage regulation.

For the DC-link voltage regulation, the actual value of $V_{P N}$ is obtained by totaling $V_{C 1}$ and $V_{C 2}$. The difference between $V_{P N}$ and the desired DC-link voltage, $V_{P N, \text { ref, }}$, is minimized by applying the PI controller. The coefficient $D_{0}$ is reached by limiting the output of the PI controller by (12).

For the AC output voltage regulation, the actual output voltages $\left(v_{A}, v_{B}, v_{C}\right)$ are utilized to calculate the actual $V_{x, p e a k}$. The abc $/ \alpha \beta$ transformation is used to obtain this work, as shown in Figure 6. In this scenario, the PI controller is also considered to generate the modulation index $M$, noted that modulation index $M$ is limited as $\left(1-D_{S T}\right)$.

After calculating three coefficients $M, D_{S T}$, and $D_{0}$, the proposed scheme can generate the control signals of inverter switches similar to the conventional scheme. Noted that the 
time intervals of NST mode 1 and NST mode 2 have been adjusted, as mentioned above, to obtain neutral voltage balance.

\section{Comparative Study}

In Section 4, the superior of the proposed method is demonstrated by comparing it to other single-stage inverters and schemes. The PWM strategies of 3L-qSBI in [27,30] are considered to make the comparison with the proposed method. The overview of boost factor, voltage gain, etc., comparison can be observed in Table 2 and Figure 7. In literature $[27,30]$, the comparison between the qSBI, ZSI, and qZSI has been already conducted. It proved that the PWM method in $[27,30]$ provides the highest boost factor and lowest component rating over other single-stage inverters. To simplify, only the PWM method in $[27,30]$ is considered in comparison to the proposed method. It should be noted that the method in [27] is implemented with a third harmonic injection scheme instead of the sinusoidal scheme. This change increases the voltage gain of the method [27] to 1.15 times and does not affect the operation of the inverter. To achieve the highest performance, the $D_{S T}$ is set to $(1-M)$ for the proposed method and the method in [27]. For the method in [30], the $D_{S T}$ is set to $2(1-M)$. In these methods, both the maximum boost and minimum boost schemes are investigated. The max boost control is achieved by setting $D_{0}$ to $\left(1-D_{S T}\right)$, and the min boost control is obtained by applying $D_{S T}$ to $D_{0}$.

Table 2. Overall comparison study of the proposed method and strategies in $[27,30]$ for $3 \mathrm{~L}-\mathrm{qSBT}^{2} \mathrm{I}$.

\begin{tabular}{cccc}
\hline & Strategy in [27] & Strategy in [30] & Proposed Method \\
\hline Max ST duty ratio, $D_{S T}$ & $1-M$ & $2(1-M)$ & $1-M$ \\
Boost factor, $B$ & $2 /\left(3-2 D_{S T}-D_{0}\right)$ & $2 /\left(3-2 D_{S T}-D_{0}\right)$ & $2 /\left(3-5 D_{S T}-D_{0}\right)$ \\
Voltage gain, $G$ & $1.15 \cdot M B$ & $1.15 \cdot M B$ & $1.15 \cdot M B$ \\
Capacitor voltage rating, $V_{c} / V_{d c}$ & $1 /\left(3-2 D_{S T}-D_{0}\right)$ & $1 /\left(3-2 D_{S T}-D_{0}\right)$ & $1 /\left(3-5 D_{S T}-D_{0}\right)$ \\
Diode voltage rating, $V_{D} / V_{d c}$ & $1 /\left(3-2 D_{S T}-D_{0}\right)$ & $1 /\left(3-2 D_{S T}-D_{0}\right)$ & $1 /\left(3-5 D_{S T}-D_{0}\right)$ \\
Switch voltage rating, $V_{S} / V_{d c}$ & $1 /\left(3-2 D_{S T}-D_{0}\right)$ & $1 /\left(3-2 D_{S T}-D_{0}\right)$ & $1 /\left(3-5 D_{S T}-D_{0}\right)$ \\
\hline
\end{tabular}

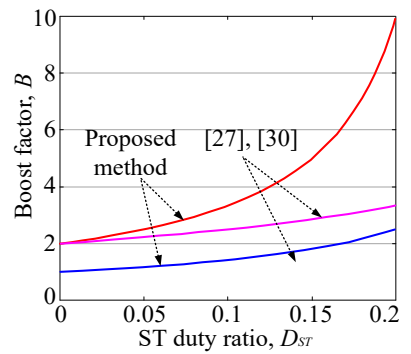

(a)

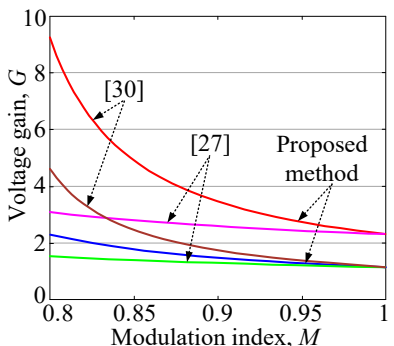

(b)

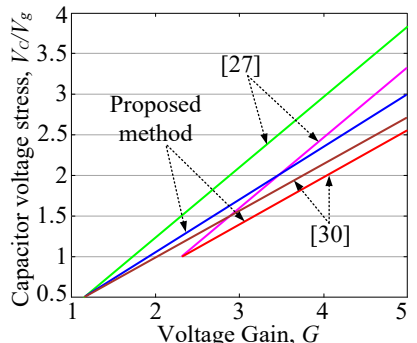

(c)

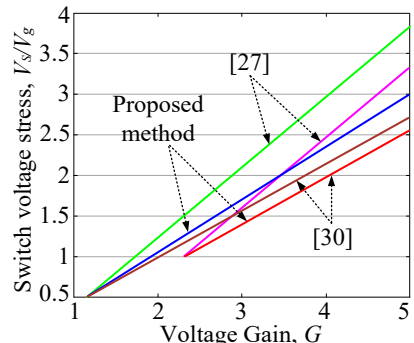

(d)

Figure 7. (a) The ST duty ratio vs boost factor, (b) modulation index vs voltage gain, (c) voltage gain vs capacitor voltage rating, and (d) voltage gain vs switch voltage rating.

As shown in Figure 7a, when applying the same ST duty ratio, the boost factors, $B$, of the methods in $[27,30]$ are the same, whereas the proposed method provides the largest boost factor. In voltage gain comparison, the proposed method and the method in [30] are the same, which is larger than that of the method in [27], for the same modulation index, $M$, as observed in Figure 7b. Due to having a larger boost factor, the proposed method needs a smaller $D_{S T}$ than that of the methods in $[27,30]$ for the same voltage gain. For example, when applying max boost control, if the proposed method needs the value $k$ for $D_{S T}$ to produce voltage $G$, the value of $D_{S T}$ for the methods in $[27,30]$ must be $(1+2 k) /(3 k)$ and $2 k$, respectively. Noted that the most conduction loss of the single-stage inverter is mostly produced in ST mode, thus having smaller $D_{S T}$ makes the proposed method produce less conduction loss than $[27,30]$.

The capacitor voltage rating comparison is illustrated in Figure 7c. It proves that the proposed scheme has smaller voltage stress on the capacitor compared to the method 
in [27]. As mentioned in Section 4, the voltage stress on impedance-source switches and diodes are the same as capacitor voltage, while voltage stresses of upper and lower switches of inverter side $S_{1 X}, S_{3 X}(X=A, B, C)$ are twice the capacitor voltage and that is half of the capacitor voltage for bidirectional switches. Therefore, the reduction of capacitor voltage stress causes a reduction of component rating of switches, as presented in Figure 7d.

In summary, the proposed method has produced the largest boost factor and voltage gain over other single-stage three-level buck-boost inverters such as ZSI and qSBIs. These advantages can cause capacitor voltage rating and semiconductor voltage rating reduction. Moreover, the largest boost factor can lead to reducing the conduction loss, which increases the overall efficiency of the inverter.

\section{Simulation and Experimental Verifications}

\subsection{Simulation Results}

With the help of PSIM simulation software, the simulation is conducted to validate the operation of the inverter under the proposed method. The simulation parameters are listed in Table 3. Both maximum and minimum boost factor control methods are validated with DC input range from $70 \mathrm{~V}$ to $200 \mathrm{~V}$. In both cases, $M$ and $D_{S T}$ are set as 0.76 and 0.15 , respectively. The extra duty ratio, $D_{0}$, of switches $S_{1}$ and $S_{2}$ is set to 0.15 and 0.85 to achieve the min and max boost factors, respectively. With these control parameters, the AC output load voltage is maintained at $110 \mathrm{~V}_{\mathrm{RMS}}$. The simulation results for both cases are shown in Figures 8 and 9 .

Table 3. Simulation and experiment parameters.

\begin{tabular}{|c|c|c|}
\hline \multicolumn{2}{|c|}{ Parameter/Components } & \multirow{2}{*}{$\frac{\text { Values }}{70 \mathrm{~V} \div 200 \mathrm{~V}}$} \\
\hline Input voltage & $\mathrm{V}_{\mathrm{g}}$ & \\
\hline Output load voltage & $\mathrm{V}_{\mathrm{x}, \mathrm{RMS}}$ & $110 \mathrm{~V}_{\mathrm{RMS}}$ \\
\hline Output frequency & $\mathrm{f}_{\mathrm{o}}$ & $50 \mathrm{~Hz}$ \\
\hline Switching frequency & $\mathrm{f}_{\mathrm{S}}$ & $10 \mathrm{kHz}$ \\
\hline Extra duty ratio & $D_{0}$ & $0.15 \div 0.85$ \\
\hline ST duty ratio & $\mathrm{D}_{\mathrm{ST}}$ & 0.15 \\
\hline Modulation index & $\mathrm{M}$ & 0.76 \\
\hline Boost inductors & $\mathrm{L}_{\mathrm{B}}$ & $3 \mathrm{mH} / 20 \mathrm{~A}$ \\
\hline Capacitors & $C_{1}=C_{2}$ & $2200 \mu \mathrm{F} / 400 \mathrm{~V}$ \\
\hline LC filter & $L_{f}$ and $C_{f}$ & $3 \mathrm{mH}$ and $10 \mu \mathrm{F}$ \\
\hline Resistor load & $\mathrm{R}$ & $56 \Omega$ \\
\hline
\end{tabular}

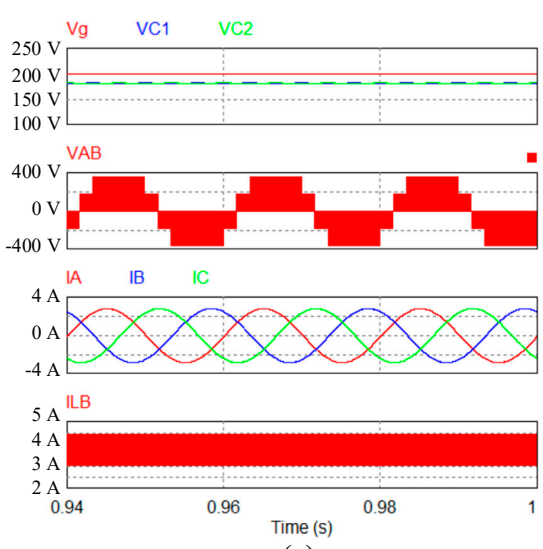

(a)
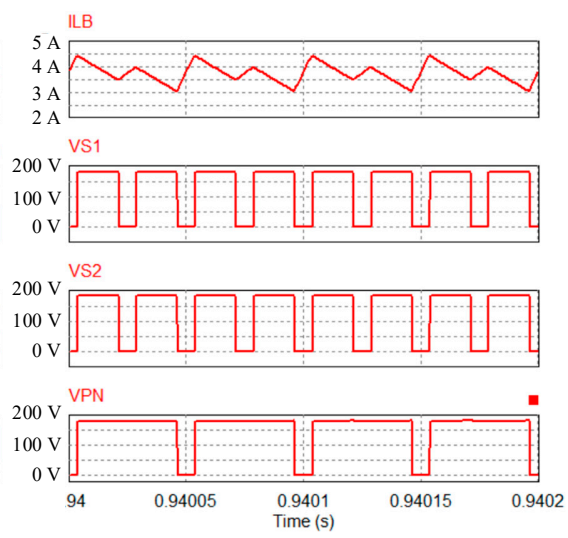

(b)

Figure 8. The simulation results of the proposed method when $V_{g}=200 \mathrm{~V}$. From top to bottom: (a) input voltage $\left(V_{g}\right)$, capacitor voltage $\left(V_{C 1}, V_{C 2}\right)$, line-to-line voltage $\left(V_{A B}\right)$, load current $\left(I_{A}, I_{B}, I_{C}\right)$, inductor current $\left(I_{L B}\right)$, (b) zoom in of inductor current $\left(I_{L B}\right)$, impedance switch voltages $\left(V_{S 1}, V_{S 2}\right)$, DC-link voltage $\left(V_{P N}\right)$. 


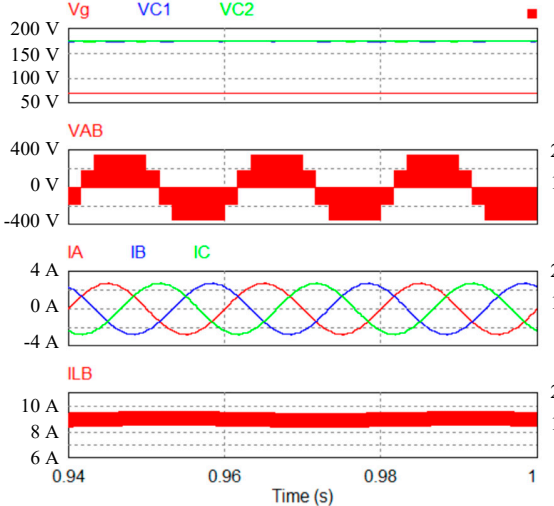

(a)

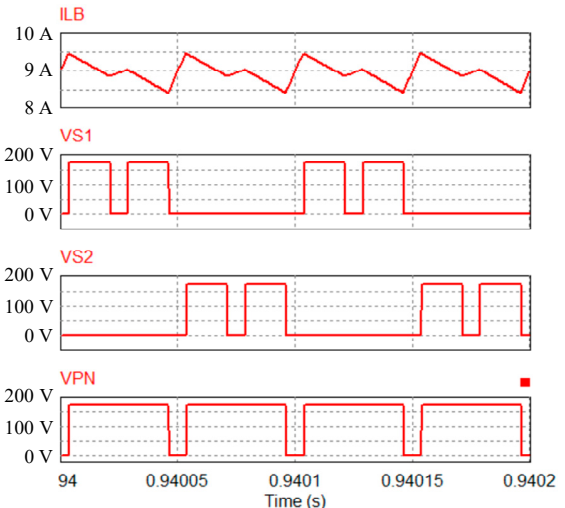

(b)

Figure 9. The simulation results of the proposed method when $V_{g}=70 \mathrm{~V}$. From top to bottom: (a) input voltage $\left(V_{g}\right)$, capacitor voltage $\left(V_{C 1}, V_{C 2}\right)$, line-to-line voltage $\left(V_{A B}\right)$, load current $\left(I_{A}, I_{B}, I_{C}\right)$, inductor current $\left(I_{L B}\right),(\mathbf{b})$ zoom in of inductor current $\left(I_{L B}\right)$, impedance switch voltages $\left(V_{S 1}, V_{S 2}\right)$, DC-link voltage $\left(V_{P N}\right)$.

In both cases, the voltages on capacitors $C_{1}$ and $C_{2}$ are boosted to $180 \mathrm{~V}$, as illustrated in Figures $8 \mathrm{a}$ and 9a. These capacitor voltages are also the voltage stresses of switches $S_{1}$ and $S_{2}$, as shown in Figures $8 \mathrm{~b}$ and $9 \mathrm{~b}$. The peak value of $V_{P N}$ is $360 \mathrm{~V}$, as illustrated in Figures $8 \mathrm{~b}$ and $9 \mathrm{~b}$. The maximum value inductor current ripple is approximately $1.5 \mathrm{~A}$ and $1 \mathrm{~A}$ for the cases of $200 \mathrm{~V}$ input voltage and $70 \mathrm{~V}$ input voltage, respectively. These values are obtained in ST mode, which is represented by the zero value of DC-link voltage, as presented in Figures $8 \mathrm{~b}$ and $9 \mathrm{~b}$. The inductor current, $I_{L B}$, is also increased in NST 3, where $S_{1}$ and $S_{2}$ are turned on simultaneously. However, it is not increased faster than that of ST mode. The average inductor current is $3.4 \mathrm{~A}$ and $9 \mathrm{~A}$ for min boost and max boost control schemes, respectively. The waveform of $V_{A B}$ is varied from $-360 \mathrm{~V}$ and $360 \mathrm{~V}$, as shown in Figures $8 \mathrm{a}$ and $9 \mathrm{a}$. The THD value of $V_{A B}$ is $66 \%$. The output load current is measured as $1.95 \mathrm{~A}_{\mathrm{RMS}}$, and its THD value is $0.56 \%$ for both cases.

The comparison of $\mathrm{CMV}, V_{\mathrm{GO}}$, between the proposed scheme and strategies in [27] and [30] is shown in Figure 10. The max boost control of methods in [27,30] is applied in the simulation. The method in [30] has the largest peak-to-peak CMV value of $200 \mathrm{~V}$. It can be explained by using small vectors that generate a large value of CMV in [30]. The peakto-peak CMV values of the scheme in [27] and the proposed PWM strategy are $130 \mathrm{~V}$ and $120 \mathrm{~V}$, respectively. The RMS CMV values of the proposed method and methods in [27,30] are $34.8 \mathrm{~V}_{\mathrm{RMS}}, 36.5 \mathrm{~V}_{\mathrm{RMS}}$, and $56.9 \mathrm{~V}_{\mathrm{RMS}}$, respectively. It is proved that the proposed PWM strategy produces the smallest CMV.

\subsection{Experimental Results}

The effectiveness of the proposed PWM strategy is also validated by experiments that are obtained through a laboratory prototype, as observed in Figure 11. The parameters used for experimental verification are also the same as simulation. The IGBTs FGL40N150 are used for the $S_{1 X}$ and $S_{3 X}$ of the inverter leg as well as the active switches of the intermediate network $\left(S_{1}\right.$ and $\left.S_{2}\right)$. The isolated voltage sensors based on LEM LV20-P sensor are used to detect the capacitor and output load voltages. The experimental results are presented in Figures 12 and 13.

For the case of a $200 \mathrm{~V}$ DC input source, as shown in Figure 12, the $V_{C 1}$ and $V_{C 2}$ are measured as $163 \mathrm{~V}$ and $170 \mathrm{~V}$, respectively, as illustrated in Figure 12a. These capacitor voltages are also the voltage stresses of switches $S_{1}$ and $S_{2}$, which are $163 \mathrm{~V}$ and $170 \mathrm{~V}$, respectively, as presented in Figure 12b. Furthermore, the max value of $V_{P N}$ is determined as $333 \mathrm{~V}$, as shown in Figure 12b. The NST mode 3 can be determined by observing the value zero of both switch $S_{1}$ and $S_{2}$ voltages, while the ST mode can be identified by observing the value zero of DC-link voltage. The inductor current is increased in both NST mode 3 and ST mode, as shown in Figure 12b. However, in ST mode, the inductor 
current increment is faster than that of NST mode 3 because the voltage across the inductor is larger than that in NST mode 3, as demonstrated in Equations (1) and (4). Inductor current ripple is measured around 1.5 A. The average value of $i_{L B}$ is measured as $3.5 \mathrm{~A}$, as presented in Figure 12a. The variation of $V_{A B}$ is from $-V_{P N}$ to $+V_{P N}$, as illustrated in Figure 12c. The output load current is measured as $1.85 \mathrm{~A}_{\mathrm{RMS}}$, and its waveform is sinusoidal. The FFT analysis for $V_{A B}$ can be seen in Figure 12c. The first-order harmonic is also the maximum value, which is $190 \mathrm{~V}$. The THD values of $V_{A B}$ and output load current $I_{A}$ are $80.5 \%$ and $2.51 \%$.

When applying $70 \mathrm{~V} D C$ input source, the capacitor $C_{1}$ and $C_{2}$ voltages are $153 \mathrm{~V}$ and $159 \mathrm{~V}$, when the coefficient $D_{0}$ is 0.85 . These voltages generate $312 \mathrm{~V}$ of DC-link voltage, as illustrated in Figure 13b. The inductor current ripple is approximately $1.1 \mathrm{~A}$, as shown in Figure 13b, and its average value is $10.4 \mathrm{~A}$, as shown in Figure 13a. The output load current is 1.71 A RMS. Figure $13 \mathrm{c}$ presents the FFT spectrum of $V_{A B}$, where the peak-to-peak value is $180 \mathrm{~V}$ at the first-order harmonic. The THD values of $V_{A B}$ and $I_{A}$ are $82.6 \%$ and $2.55 \%$, respectively.

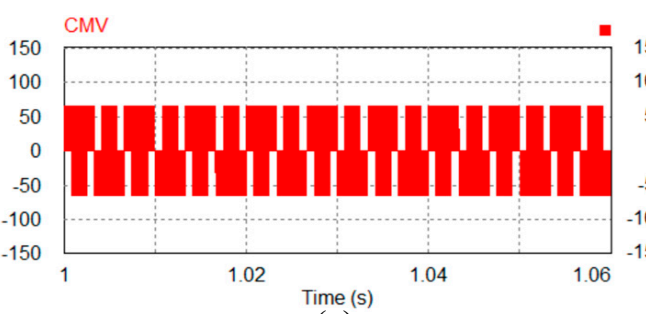

(a)

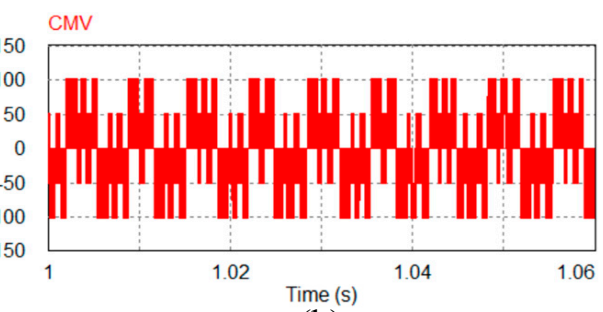

(b)

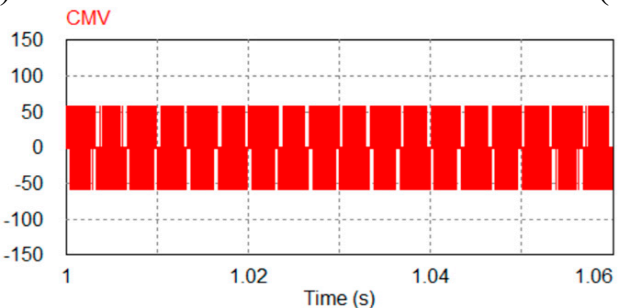

(c)

Figure 10. CMV comparison between (a) the method in [27], (b) the method in [30], and (c) the proposed method.

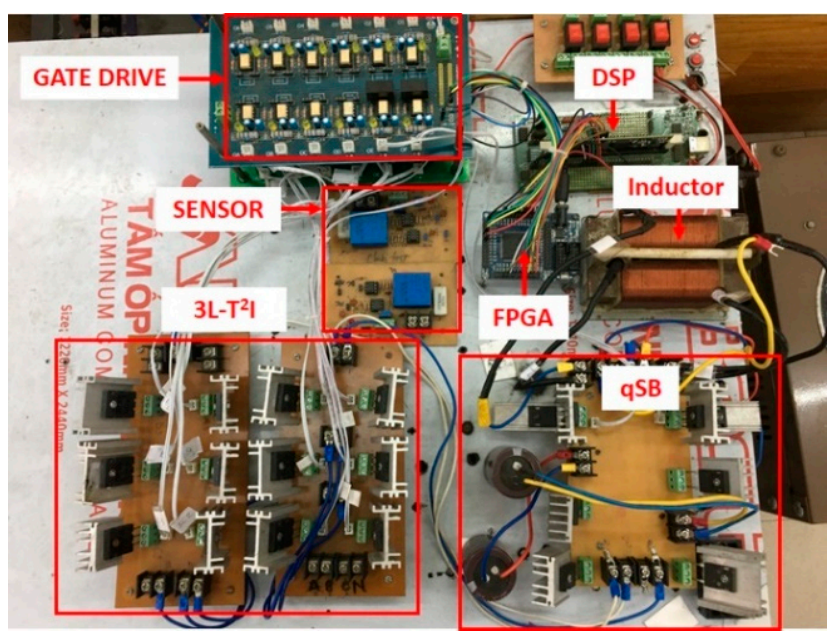

Figure 11. Experimental prototype. 


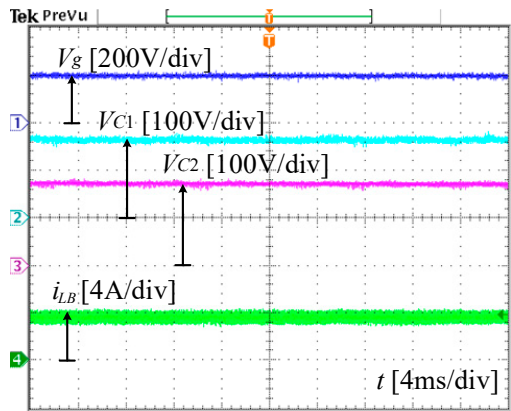

(a)

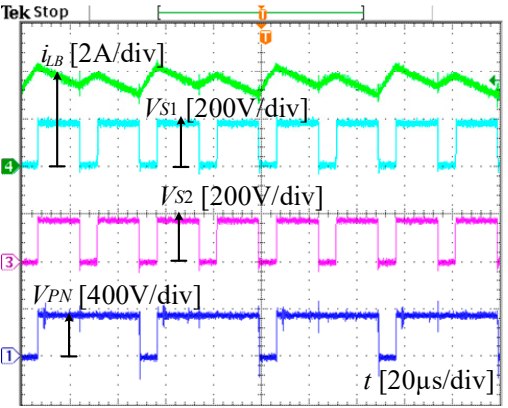

(b)

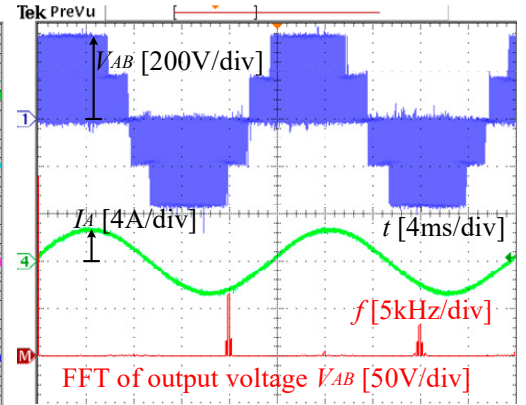

(c)

Figure 12. Experimental results of the inverter under the proposed method when $V_{g}=200 \mathrm{~V}$. From the top to bottom: (a) $V_{g}$, $V_{C 1}, V_{C 2}$, and $i_{L B} ;(\mathbf{b}) i_{L B}, V_{S 1}, V_{S 2}$, and $V_{P N} ;$ (c) $V_{A B}, I_{A}$, and FFT spectrum of the output voltage $V_{A B}$.

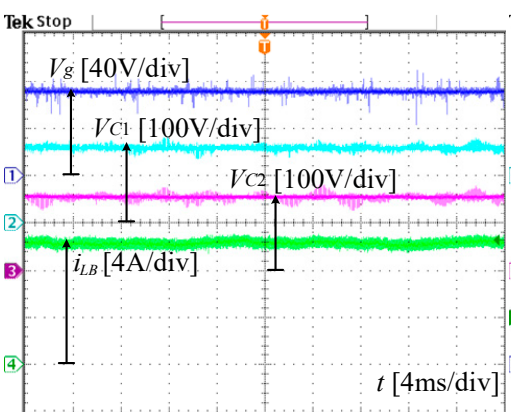

(a)

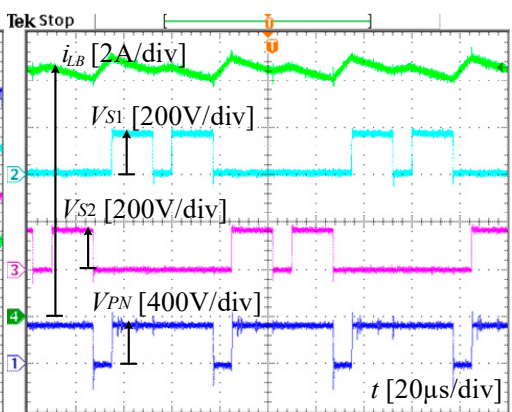

(b)

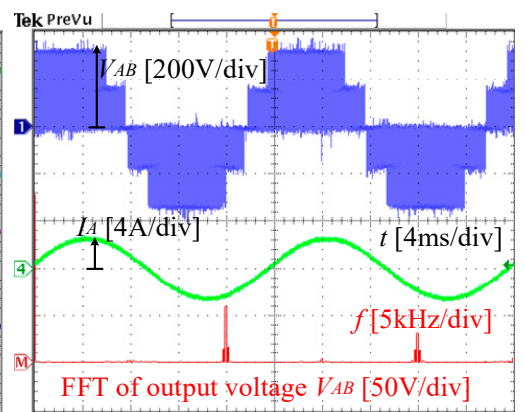

(c)

Figure 13. Experimental results of the inverter under the proposed method when $V_{g}=70 \mathrm{~V}$. From the top to bottom: (a) $V_{g}$, $V_{C 1}, V_{C 2}$, and $i_{L B} ;(\mathbf{b}) i_{L B}, V_{S 1}, V_{S 2}$, and $V_{P N} ;$ (c) $V_{A B}, I_{A}$, and FFT spectrum of the output voltage $V_{A B}$.

The capacitor voltage balance scheme and the closed-loop control implementation for the proposed method have been conducted. The results are shown in Figures 14 and 15. The neutral voltage control is implemented in two cases: (1) the difference voltage between these capacitors $v_{\text {dif }}$ is positive, and (2) the difference voltage between these capacitors $v_{\text {dif }}$ is negative. In both cases, the neutral voltage balance condition is recovered after approximately $20 \mathrm{~ms}$, as shown in Figure 14a,b. These results are conducted with the coefficient $\alpha$ of 0.3 .

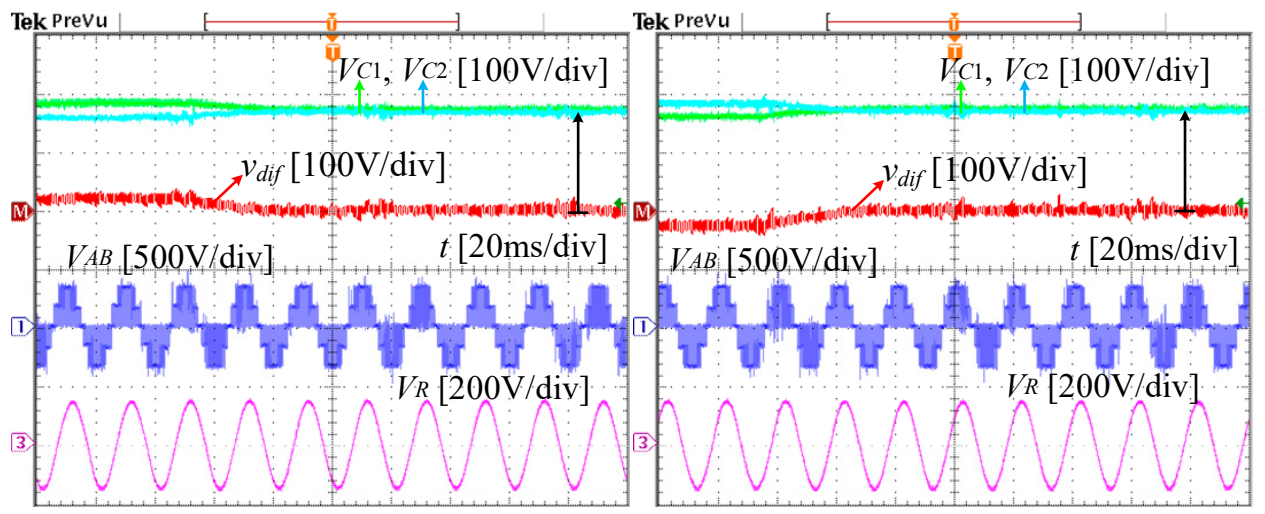

(a)

(b)

Figure 14. The experimental results for capacitor voltage balance. (a) $v_{d i f}>0,(\mathbf{b}) v_{d i f}<0$. 


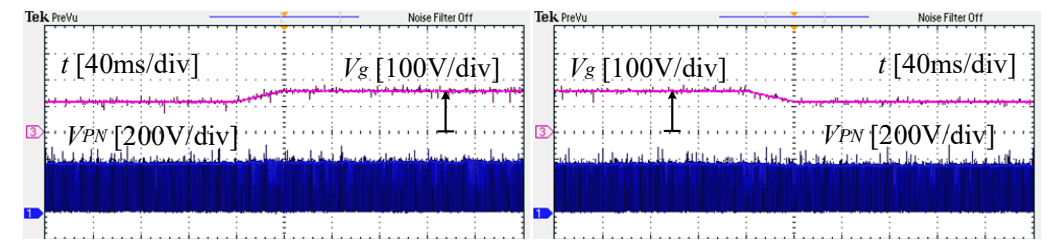

(a)

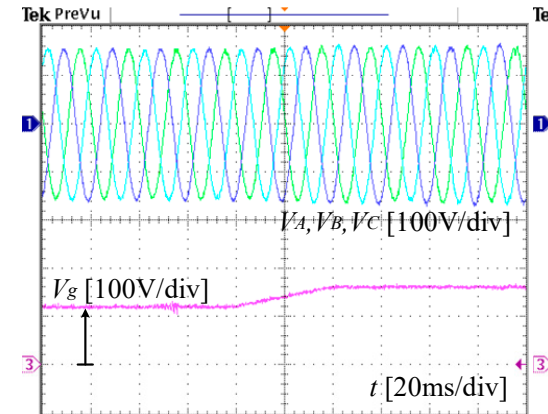

(c) (b)

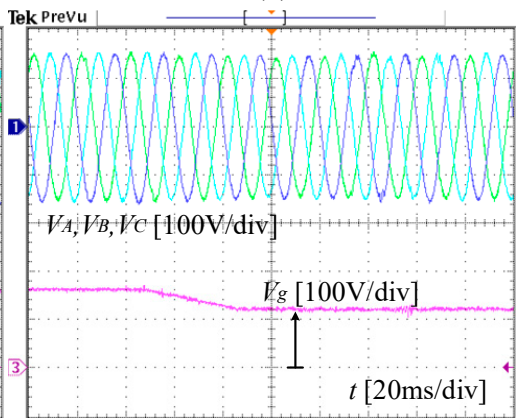

(d)

Figure 15. The experimental verification for DC-link voltage control and output load voltage control. $(\mathbf{a}, \mathbf{c})$ Input voltage increment, $(\mathbf{b}, \mathbf{d})$ input voltage decrement.

The input voltage is regulated to increase from $120 \mathrm{~V}$ to $160 \mathrm{~V}$ and decrease from $160 \mathrm{~V}$ to $120 \mathrm{~V}$ to validate the closed-loop control. In both cases, the $V_{P N}$ is maintained at $360 \mathrm{~V}$, which can be seen from Figure 15a,b. The output load voltage is kept at $110 \mathrm{~V}_{\mathrm{RMS}}$ without DC input voltage variation, as presented in Figure $15 \mathrm{c}, \mathrm{d}$. In this work, the ST duty ratio $D_{S T}$ is kept at 0.15 . The modulation index is used to regulate the output load voltage and is limited to 0.85 . The coefficient $D_{0}$ is utilized to control DC-link voltage, and its range is from 0.15 to 0.85 .

\section{Conclusions}

This paper has introduced a PWM method for the 3L-qSBT ${ }^{2}$ I based on a third harmonic injection scheme. By applying this method, many benefits have been obtained, such as high boost factor, high voltage gain, and less voltage rating on impedance-source network devices. These advantages have been validated through some investigations, which were conducted belonging to previous publications. The details of relevant equations and designed parameter selection have been presented. Furthermore, this paper also considered the capacitor voltage unbalance problem. The time interval of NST mode, which is generated by triggering only one switch of the qSB network, has been recalculated based on the actual capacitor voltages to provide neutral voltage balance characteristics. The output voltage and DC-link voltage have been controlled by using PI controllers. The extra duty cycle of two active switches of the qSB network was adopted to regulate DC-link voltage, whereas the modulation index has been utilized to regulate the AC output voltage. The accuracy of this scheme has been validated by simulation and experimental results. With some benefits listed, such as buck-boost operation, reduced conduction loss, the low voltage stress on devices, and an easy capacitor voltage balance scheme, the 3L-qSBT ${ }^{2} \mathrm{I}$ under the proposed method is suitable for PV applications where a low DC input voltage needs to be converted to a high AC output voltage with high efficiency and output quality.

Author Contributions: This article has received the same contributions from the authors. which include writing the paper and experiment implementation. This manuscript has been received agreement from all authors. This paper was a collaborative effort among all authors. D.-T.D., V.-T.T. and M.-K.N. conceived the methodology, conducted the performance tests and wrote the paper. All authors have read and agreed to the published version of the manuscript.

Funding: This research was funded by T2020-18TĐ project.

Institutional Review Board Statement: Not applicable. 
Informed Consent Statement: Not applicable.

Data Availability Statement: This work was supported by the Advanced Power Electronics Laboratory, D405 at Ho Chi Minh City University of Technology and Education, Viet Nam.

Conflicts of Interest: The authors declare no conflict of interest.

\section{References}

1. Zhang, Z.; Zhang, J.; Shao, S. A Novel Trapezoidal Wave Control Method for a Single-Phase Grid-Tied T-Type Inverter. IEEE Trans. Power Electron. 2021, 36, 4711-4722. [CrossRef]

2. Wang, Z.; Wu, Y.; Mahmud, M.H.; Zhao, Z.; Zhao, Y.; Mantooth, H.A. Design and Implementation of a Highly Efficient Three-Level T-Type Converter for Low-Voltage Applications. IEEE J. Emerg. Sel. Top. Power Electron. 2020, 8, 578-588. [CrossRef]

3. Nemade, R.V.; Pandit, J.K.; Aware, M.V. Reconfiguration of T-Type Inverter for Direct Torque Controlled Induction Motor Drives under Open-Switch Faults. IEEE Trans. Ind. Appl. 2017, 53, 2936-2947. [CrossRef]

4. Li, X.; Xing, X.; Zhang, C.; Chen, A.; Qin, C.; Zhang, G. Simultaneous Common-Mode Resonance Circulating Current and Leakage Current Suppression for Transformerless Three-Level T-Type PV Inverter System. IEEE Trans. Ind. Electron. 2019, 66, 4457-4467. [CrossRef]

5. Xing, X.; Zhang, C.; Chen, A.; Geng, H.; Qin, C. Deadbeat Control Strategy for Circulating Current Suppression in Multiparalleled Three-Level Inverters. IEEE Trans. Ind. Electron. 2018, 65, 6239-6249. [CrossRef]

6. Roncero-Clemente, C.; Romero-Cadaval, E.; Ruiz-Cortés, M.; Husev, O. Carrier Level-Shifted Based Control Method for the PWM 3L-T-Type qZS Inverter with Capacitor Imbalance Compensation. IEEE Trans. Ind. Electron. 2018, 65, 8297-8306. [CrossRef]

7. Ding, X.; Hao, Y.; Li, K.; Li, H.; Wei, Z.; Wu, W. Extensible Z-Source Inverter Architecture: Modular Construction and Analysis. IEEE Trans. Power Electron. 2021, 36, 1742-1763. [CrossRef]

8. Peng, F.Z. Z-source inverter. IEEE Trans. Ind. Appl. 2003, 39, 504-510. [CrossRef]

9. Mahmoudi, H.; Aleenejad, M.; Ahmadi, R. Modulated Model Predictive Control for a Z-Source-Based Permanent Magnet Synchronous Motor Drive System. IEEE Trans. Ind. Electron. 2018, 65, 8307-8319. [CrossRef]

10. Singh, S.A.; Carli, G.; Azeez, N.A.; Williamson, S.S. Modeling, Design, Control, and Implementation of a Modified Z-Source Integrated PV/Grid/EV DC Charger/Inverter. IEEE Trans. Ind. Electron. 2018, 65, 5213-5220. [CrossRef]

11. Birundha, S.; Saravanan, V. Design and development of Z source cascaded seven level inverter for solar photovoltaic system. In Proceedings of the 2015 International Conference on Computation of Power, Energy, Information and Communication (ICCPEIC), Melmaruvathur, Chennai, India, 22-23 April 2015; pp. 87-92.

12. Loh, P.C.; Gao, F.; Blaabjerg, F.; Feng, S.Y.C.; Soon, K.N.J. Pulsewidth-Modulated Z-Source Neutral-Point-Clamped Inverter. IEEE Trans. Ind. Appl. 2007, 43, 1295-1308. [CrossRef]

13. Loh, P.C.; Lim, S.W.; Gao, F.; Blaabjerg, F. Three-Level Z-Source Inverters Using a Single LC Impedance Network. IEEE Trans. Ind. Electron. 2007, 22, 706-711. [CrossRef]

14. Annam, S.K.; Pongiannan, R.K.; Yadaiah, N. A Hysteresis Space Vector PWM for PV Tied Z-Source NPC-MLI with DC-Link Neutral Point Balancing. IEEE Access 2021, 9, 54420-54434. [CrossRef]

15. Effah, F.B.; Wheeler, P.; Clare, J.; Watson, A. Space-Vector-Modulated Three-Level Inverters with a Single Z-Source Network. IEEE Trans. Ind. Electron. 2013, 28, 2806-2815. [CrossRef]

16. Xing, X.; Zhang, C.; Chen, A.; He, J.; Wang, W.; Du, C. Space-Vector-Modulated Method for Boosting and Neutral Voltage Balancing in Z-Source Three-Level T-Type Inverter. IEEE Trans. Ind. Appl. 2016, 52, 1621-1631. [CrossRef]

17. Stepenko, S.; Husev, O.; Vinnikov, D.; Fesenko, A.; Clemente, C.R.; Pimentel, S.P.; Santasheva, E. Experimental Comparison of Two-Level Full-SiC and Three-Level Si-SiC Quasi-Z-Source Inverters for PV Applications. Energies 2019, 12, 2509. [CrossRef]

18. Stepenko, S.; Husev, O.; Vinnikov, D.; Fesenko, A.; Matiushkin, O. Feasibility Study of Interleaving Approach for Quasi-Z-Source Inverter. Electronics 2020, 9, 277. [CrossRef]

19. Pires, V.F.; Cordeiro, A.; Foito, D.; Martins, J.F. Quasi-z-Source Inverter with a T-Type Converter in Normal and Failure Mode. IEEE Trans. Power Electron. 2016, 31, 7462-7470. [CrossRef]

20. Wang, T.; Wang, X.; He, Y.; Chen, X.; Ruan, X.; Zhang, Z. An Improved Quasi-Z-Source Three-Level T-Type Inverter and Its Modulation Scheme. In Proceedings of the 2020 IEEE Applied Power Electronics Conference and Exposition (APEC), New Orleans, LA, USA, 15-19 March 2020; pp. 412-416.

21. Qin, C.; Zhang, C.; Chen, A.; Xing, X.; Zhang, G. A Space Vector Modulation Scheme of the Quasi-Z-Source Three-Level T-Type Inverter for Common-Mode Voltage Reduction. IEEE Trans. Ind. Electron. 2018, 65, 8340-8350. [CrossRef]

22. Qin, C.; Zhang, C.; Xing, X.; Li, X.; Chen, A.; Zhang, G. Simultaneous Common-Mode Voltage Reduction and Neutral-Point Voltage Balance Scheme for the Quasi-Z-Source Three-Level T-Type Inverter. IEEE Trans. Ind. Electron. 2020, 67, 1956-1967. [CrossRef]

23. Nguyen, M.K.; Lim, Y.C.; Park, S.J. A Comparison between Single-Phase Quasi- Z-Source and Quasi-Switched Boost Inverters. IEEE Trans. Ind. Electron. 2015, 62, 6336-6344. [CrossRef]

24. Tran, V.T.; Do, D.T.; Do, V.D.; Nguyen, M.K. A Three-Level DC-Link Quasi-Switch Boost T-Type Inverter with Voltage Stress Reduction. Energies 2020, 13, 3727. [CrossRef] 
25. Sahoo, M.; Keerthipati, S. A Three-Level LC-Switching-Based Voltage Boost NPC Inverter. IEEE Trans. Ind. Electron. 2017, 64, 2876-2883. [CrossRef]

26. Sahoo, M.; Kumar, S. A single source fed three level voltage boost NPC inverter with reduced LC count. In Proceedings of the IECON 2016-42nd Annual Conference of the IEEE Industrial Electronics Society, Florence, Italy, 23-26 October 2016; pp. 3190-3195.

27. Do, D.T.; Nguyen, M.K. Three-Level Quasi-Switched Boost T-Type Inverter: Analysis, PWM Control, and Verification. IEEE Trans. Ind. Electron. 2018, 65, 8320-8329. [CrossRef]

28. Do, D.T.; Nguyen, M.K.; Ngo, V.T.; Quach, T.H.; Tran, V.T. Common Mode Voltage Elimination for Quasi-Switch Boost T-Type Inverter Based on SVM Technique. Electronics 2020, 9, 76. [CrossRef]

29. Do, D.T.; Nguyen, M.K.; Quach, T.H.; Tran, V.T.; Blaabjerg, F.; Vilathgamuwa, D.M. A PWM Scheme for a Fault-Tolerant Three-Level Quasi-Switched Boost T-Type Inverter. IEEE J. Emerg. Sel. Top. Power Electron. 2019, 8, 3029-3040. [CrossRef]

30. Tran, V.T.; Nguyen, M.K.; Do, D.T.; Vinnikov, D. An SVM Scheme for Three-Level Quasi-Switched Boost T-Type Inverter with Enhance Voltage Gain and Capacitor Voltage Balance. IEEE Trans. Power Electron. 2021, in press. [CrossRef] 